\title{
Temporal Properties of Cerebellar-Dependent Memory Consolidation
}

\author{
Samuel F. Cooke, ${ }^{1}$ Phillip J. E. Attwell, ${ }^{2}$ and Christopher H. Yeo ${ }^{2}$ \\ ${ }^{1}$ Division of Neurophysiology, The National Institute for Medical Research, London NW7 1AA, United Kingdom, and ${ }^{2}$ Department Anatomy and \\ Developmental Biology, University College London, London WC1E 6BT, United Kingdom
}

\begin{abstract}
Classical conditioning of the nictitating membrane response in rabbits is a well defined model of cerebellar-dependent motor memory. This memory undergoes a period of consolidation after the training session, when it is sensitive to reversible inactivations of the cerebellar cortex, but not of the cerebellar nuclei, with the $\mathrm{GABA}_{\mathrm{A}}$ receptor agonist muscimol. Here, the temporal properties of this cerebellar cortex-dependent consolidation were examined using delayed infusions of muscimol in cortical lobule HVI. Cortical infusions delayed by 5 or $45 \mathrm{~min}$ after a conditioning session produced significant and very similar impairments of consolidation, but infusions delayed by 90 min produced little or no impairment. Behavioral measures indicate that the muscimol infusions produced significant effects after $\sim 30 \mathrm{~min}$ and they lasted for a few hours. So, over a time window beginning $\sim 1 \mathrm{hr}$ after the end of the training session and closing $1 \mathrm{hr}$ after that, intracortical activity is critical for consolidation of this motor memory.
\end{abstract}

Key words: motor learning; consolidation; classical conditioning; nictitating membrane; muscimol; olivo-cortico-nuclear loop; time window

\section{Introduction}

Many forms of motor learning are critically dependent on the cerebellum, but it is still unclear how motor memories are formed and stored within the cerebellar circuitry. Classical conditioning of the rabbit eyeblink and nictitating membrane response (NMR) is a useful model of cerebellar-dependent learning. Local, reversible inactivations of specific cerebellar cortical (Attwell et al., 2001), cerebellar nuclear (Krupa et al., 1993), or olivary (Welsh and Harvey, 1998) regions during training all prevent the acquisition of eyeblink NMR conditioning, as measured by an absence of conditioned responses (CRs) after recovery from the inactivations.

Failures to acquire and express CRs while discrete regions of the cortex, nuclei, or olive are dysfunctional, however, do not necessarily indicate that memory storage is distributed across all of these levels. Following a plan common to all parts of the cerebellum (Voogd and Glickstein, 1998), these regions are connected to form an olivo-cortico-nuclear eyeblink control module (Yeo and Hesslow, 1998), and potent regulation of olivo-cortical transmission by an inhibitory nucleo-olivary feedback (Andersson et al., 1988) completes an olivo-cortico-nucleo-olivary (OCNO) loop. Thus, pharmacological manipulation at any node disturbs activity throughout the loop. So the equivalence of cortical, nuclear, and olivary inactivations in preventing the acqui-

Received Dec. 15, 2003; revised Dec. 15, 2003; accepted Feb. 12, 2004.

This study was supported by Grants 31/S10225 and 31/GAN13106 and a studentship awarded to S.C. by the Biotechnology and Biological Sciences Research Council, UK.

Correspondence should be addressed to Christopher Yeo, University College London, Department of Anatomy and Developmental Biology, Gower Street, London WC1E 6BT, UK. E-mail: c.yeo@ucl.ac.uk.

DOI:10.1523/JNEUROSCI.5505-03.2004

Copyright $\odot 2004$ Society for Neuroscience $\quad 0270-6474 / 04 / 242934-08 \$ 15.00 / 0$ sition of NMR conditioning points to a requirement for a fully functional OCNO loop but does not localize the plasticity.

Recently, however, cortical and nuclear functions in conditioning have been dissociated by manipulating post-training, consolidation processes. Inactivation of neurons in cortical lobule HVI, using the $\mathrm{GABA}_{\mathrm{A}}$ receptor agonist muscimol, immediately after each of four training sessions prevented the development of CRs, but similar post-training inactivation of the anterior interpositus nucleus did not (Attwell et al., 2002a). So normal activity around the OCNO loop is important for the acquisition of this motor memory but not for its consolidation. Thus, intrinsic cerebellar cortical processes are implicated in the consolidation, consistent with long-standing proposals that motor learning relies on plasticity in the cerebellar cortex (Marr, 1969; Albus, 1971; Ito, 1982). What post-encoding processes within the cerebellar cortex are sensitive to manipulations of GABA transmission and are essential for memory formation?

A first step in answering this question is to define the temporal properties of these cortical consolidation processes. A consolidation time window has been identified for rabbit NMR conditioning using systemic post-training drug treatments (Scavio et al., 1992), and although they would not have selectively affected cerebellar processes, they suggest a time window during which consolidation of NMR conditioning is sensitive to these drugs and that closes $\sim 2 \mathrm{hr}$ after a training session.

Here we identify the onset and offset of the cerebellar cortical, GABA-sensitive consolidation processes (Attwell et al., 2002a) by delaying the delivery of cortical muscimol infusions to allow periods within which consolidation might occur. We reveal a discrete time window for consolidation processes mediated by the cerebellar cortex and essential for the formation of a motor memory. 


\section{Materials and Methods}

Experimental and control groups

In our previous study (Attwell et al., 2002a), cerebellar cortical lobule HVI was inactivated 5 min after conditioning sessions. To make comparisons with those data, all protocols here were identical to those of the previous study, except that post-training inactivations were delayed by 45 or $90 \mathrm{~min}$. Data from the previous ( 5 min delay) subjects are presented here again to enable comparison and further statistical analysis. Vehicle infusion controls include those from the previous study together with three additional subjects. All procedures conformed to UK Home Office, Animal Procedures regulations.

\section{Surgery}

Male Dutch belted rabbits $(2.0-2.2 \mathrm{~kg})$ were implanted with a guide cannula directed toward the right cerebellar cortical lobule HVI $(n=27)$. After intubation under fentanyl/fluanisone anesthesia $(0.1 / 5.0 \mathrm{mg} / \mathrm{kg}$, i.m.), supplemented with benzodiazepam $(0.5 \mathrm{mg} / \mathrm{kg}$, i.v. $)$, each subject received mannitol $(10-20 \mathrm{ml}$, i.v.; $1 \mathrm{ml} / \mathrm{min})$ and enrofloxacin antibiotic (20 mg, i.p.). The rabbit's head was placed in a head holder, and anesthesia was maintained throughout the operation using halothane (1.5-2.5\%) in a nitrous oxide/oxygen mixture (1:3). The scalp was reflected, and bone and dura were removed to expose the right cerebellar cortex. A 26 ga stainless steel cannula guide (Plastics One, Roanoke, VA) was then implanted by visual inspection just below the surface of the lobule. The cannula guide was fixed to the skull with dental cement, and the scalp was sutured around the implant. Each animal received analgesic and antibiotic cover for $3 \mathrm{~d}$ after the operation (buprenorphine hydrochloride, $0.1 \mathrm{mg} / \mathrm{d}$, and enrofloxacin, $20 \mathrm{mg} / \mathrm{d}$ ). All subjects were housed individually, allowed food and water ad libitum, and maintained on a 12 $\mathrm{hr}$ light/dark cycle for at least 1 week before surgery and throughout the experiment.

\section{Conditioning protocols}

The apparatus and techniques used for conditioning experiments were similar to those first developed by Gormezano et al. (1962) and have been described previously (Yeo and Hardiman, 1992). In each subject a monofilament loop was sutured in the right nictitating membrane under local anesthesia (proxymetacaine hydrochloride, $0.5 \% \mathrm{w} / \mathrm{v}$ ). Subjects were held in a close-fitting Perspex restraining stock, and a low-torque potentiometer was attached to the head by clips around the ears and muzzle. Each subject was placed in a ventilated, sound-attenuating chamber facing a centrally mounted loudspeaker. The conditioned stimulus (CS) was a $1 \mathrm{kHz}$ sine wave tone of $410 \mathrm{msec}$ duration and an intensity of $81 \mathrm{~dB}$ (A-scale). Background noise produced by ventilation fans was $57 \mathrm{~dB}$ (A-scale). The unconditioned stimulus (US) was periorbital electrical stimulation ( $60 \mathrm{msec}$ train of three biphasic pulses of intensity $2 \mathrm{~mA}$ ) through stainless steel clips attached to the skin, one immediately behind the temporal canthus of the eye, the other immediately below the center of the lower eyelid. On paired trials the interstimulus interval between the CS and US onset was $350 \mathrm{msec}$. The intertrial interval was randomly selected between 25 and $35 \mathrm{sec}$.

\section{Habituation session}

Before conditioning training commenced, a single habituation session (session 0) of $25 \mathrm{~min}$ allowed adaptation to the novel environment of the chamber. During this period each subject was placed in the restraining stock within the conditioning chamber and the nictitating membrane transducer was fitted. The periorbital clips were attached, but the US and CS were not presented.

\section{Conditioning sessions}

Each conditioning session consisted of 50 trials. In 45 trials the CS and US were paired, and in 5 trials the CS was presented alone. A CS-alone trial was presented on every 10th trial. The acquisition training consisted of four phases with $3 \mathrm{~d}$ between each phase.

Phase 1. All subjects received four daily sessions of acquisition training. After each session, group 5 (from the previous study), group 45, and group 90 subjects received a cortical infusion of muscimol $(3.5 \mathrm{~mm} ; 2 \mu \mathrm{l}$ in $0.01 \mathrm{~m}$ PBS, pH 7.4) 5, 45, or $90 \mathrm{~min}$, respectively, after the end of the session. Group S subjects received vehicle (PBS, $2 \mu \mathrm{l}) 5 \mathrm{~min}$ after each session. All infusions were given over $2 \mathrm{~min}$.

Phase 2. All subjects received four daily sessions of training with no post-training infusions.

Phase 3. Experimental group 5, 45, and 90 subjects, which had received muscimol during Phase 1, received four additional daily sessions of training without drug.

Phase 4. To test whether the muscimol infusions in Phase 1 had been in appropriate locations and fully sufficient to inactivate the critical eyeblink control regions, we tested in Phase 4 their efficacy in blocking the performance of conditioned responses that had been established previously in Phases 1 and 2. The Phase 4 session began with 20 trials (18 paired CS-US trials and 2 unpaired CS trials). Muscimol (same dose, concentration, and time course as in Phase 1) was then infused. Five minutes after the start of the infusion, the session continued with 20 trials (18 paired CS-US and 2 unpaired CS). Similar blocks of 20 trials were then given at $30 \mathrm{~min}, 1,2,4,8$, and $24 \mathrm{hr}$ after the infusion. In this way, the effects of muscimol infusion were assessed throughout its time to effects and recovery.

\section{Histology}

In the final stage of the experiment, $\left[{ }^{3} \mathrm{H}\right]$ muscimol in PBS ( $7 \mathrm{nmol}$ in $2 \mu \mathrm{l}$ PBS, containing $1 \mu \mathrm{Ci} / \mu \mathrm{l}$ ) was infused through the injection cannulas for all subjects at the same position as for the previous infusions. This muscimol dose corresponded to the concentration used in the experimental phases. Each subject was then given heparin sodium (500 U/kg, i.v.) and an overdose of pentobarbitone sodium $(90 \mathrm{mg} / \mathrm{kg}$, i.v. $) 2 \mathrm{hr}$ after the end of the muscimol infusion. This time corresponded to the maximum drug effect on behavior during Phase 5 . Each subject was perfused transcardially with $0.9 \%$ saline ( 11 l) followed by $4 \%$ formaldehyde solution (2 l). The brain was removed, embedded in gelatin, and cryoprotected in $20 \%$ sucrose solution, and then serial $50 \mu \mathrm{m}$ frozen transverse sections were cut.

\section{Autoradiography and image analysis}

Every sixth brain section was opposed to tritium-sensitive film (Hyperfilm, Amersham Biosciences, Arlington Heights, IL) for autoradiography together with tritium standards (Microscales, Amersham Biosciences) for 6 weeks at $4^{\circ} \mathrm{C}$. After film development, the sections were stained with cresyl violet. The autoradiograph of every brain section was imaged with a monochrome CCD camera and analyzed using standard densitometry techniques (AIS, Imaging Research); the resultant images were calibrated, and their densities were color coded with reference to the tritium standards as picomoles of muscimol per milligrams of tissue equivalent (see Fig. 2).

An image of each Nissl-stained section was captured and processed to reveal the brain edges and granule cell layer boundaries. Composites of the color-coded densitometry and the brain contours were then made.

\section{Data analysis}

A CR was defined as an NMR within the CS-US interval with amplitude $\geq 0.5 \mathrm{~mm}$ and with onset latency $>35 \mathrm{msec}$ from CS onset (Yeo and Hardiman, 1992). CR frequency (\%CRs) was calculated for each block of nine paired trials throughout the conditioning sessions.

Data across Phases 1 and 2 were analyzed using Kruskal-Wallis oneway ANOVA on ranks tests for main group effects during relevant phases of testing followed, when significant, by Dunn's post hoc multiple comparisons procedure to determine individual changes. Day 5 data analysis used one-way ANOVA followed by Fisher's least significant difference post hoc tests.

\section{Results}

\section{Experimental design}

The experimental design matched that used in our previous study (Attwell et al., 2002a), in which infusions of muscimol ( $7 \mathrm{nmol} ; 2$ $\mu \mathrm{l})$ into lobule HVI of the cerebellar cortex 5 min after training had prevented learning of the classically conditioned NMR. Here, there were three experimental groups. Group 45 subjects received muscimol ( $7 \mathrm{nmol} ; 2 \mu \mathrm{l}$ ) infusions into lobule HVI 45 min after 
conditioning, and group 90 subjects received similar infusions 90 min after conditioning. Control group $S$ subjects received $2 \mu$ linfusions of vehicle 5 min after conditioning. For purposes of comparison, data from the previously published, 5-min-delay muscimol treatment are referred to here as from group 5.

There were four experimental phases (Fig. 1), each separated by a $3 \mathrm{~d}$ rest period. Phase 1 consisted of four daily conditioning sessions of 50 trials. Each session lasted $25 \mathrm{~min}$ and contained 45 CS-US (auditory tone and periocular electrical stimulation, respectively) paired trials and 5 unpaired, CS-alone trials. Each conditioning session in Phase 1 was followed by infusions of muscimol after 45 min (group 45) or 90 min (group 90). Group S subjects received saline infusions after a 5 min delay. The muscimol infusions would be effective, therefore, during the post-training, putative consolidation period. During Phase 2, all subjects received four additional sessions of training, this time without infusions. If consolidation had been impaired during Phase 1, then performance would be at baseline levels at the start of Phase 2 and learning should then progress from the naive condition. Group S control subjects finished training at the end of this stage. Subjects from groups 45 and 90 (and group 5 from the previous study) received additional training but no infusions during Phase 3.

All subjects should have reached asymptotic levels of CRs in Phase 3. So finally, in Phase 4, muscimol was again infused in all subjects from groups 45 and 90 , but this time before a conditioning session. The drug effects on CR performance during this session, and at time points over the next $24 \mathrm{hr}$, were monitored to assess whether during this and earlier phases the drug had been delivered to the appropriate eyeblink control regions in the cerebellar cortex.

\section{Infusion sites, infusion efficacies, and cannulation-related damage}

Cannulations and infusions were required to satisfy three criteria for inclusion in the experiment. These criteria ensured that the critical cerebellar regions, and only those regions, were affected by the infusions.

(1) The infusions should be restricted to the cerebellar cortex. Muscimol inactivation of the cerebellar nuclei successfully blocks expression of CRs but does not impair consolidation (Attwell et al., 2002a). Thus, effective CR block in Phase 4 is not, in itself, a sufficient test of the efficacy of the effects of the drug on the cortex; migration of the drug into the cerebellar nuclei must be excluded. This criterion was tested by analysis of the $\left[{ }^{3} \mathrm{H}\right]$ muscimol infusion spreads by quantitative autoradiography. Any signal level above background within the cerebellar nuclei was reason to exclude that subject from its experimental group. This deliberately conservative strategy required no assumptions about the correlation between levels of bound drug and their physiological effects, and a recent study that combined electrophysiological recording of the cerebellar cortex with local infusions of muscimol revealed that autoradiography of radiolabeled muscimol provides an accurate estimate of the drug spread (Arikan et al., 2002). Drug spread in subjects from groups 45 and 90 is shown in Figure 2 and has been reported previously for group 5 (Attwell et al., 2002a). Location of the cannula tips for all groups is shown in Figure 3. The location of cannula tips is comparable and spread of the drug is similar across all groups.

(2) The muscimol infusions should be effective in blocking function in the critical cerebellar cortical regions. This criterion was tested in Phase 4. Only if muscimol fully blocked expression of conditioned responses for at least one block of 10 trials in the post-infusion period was each subject admitted to its experimental group.

(3) The cannulation should not have produced permanent damage sufficient to invalidate assessment of cerebellar function. 

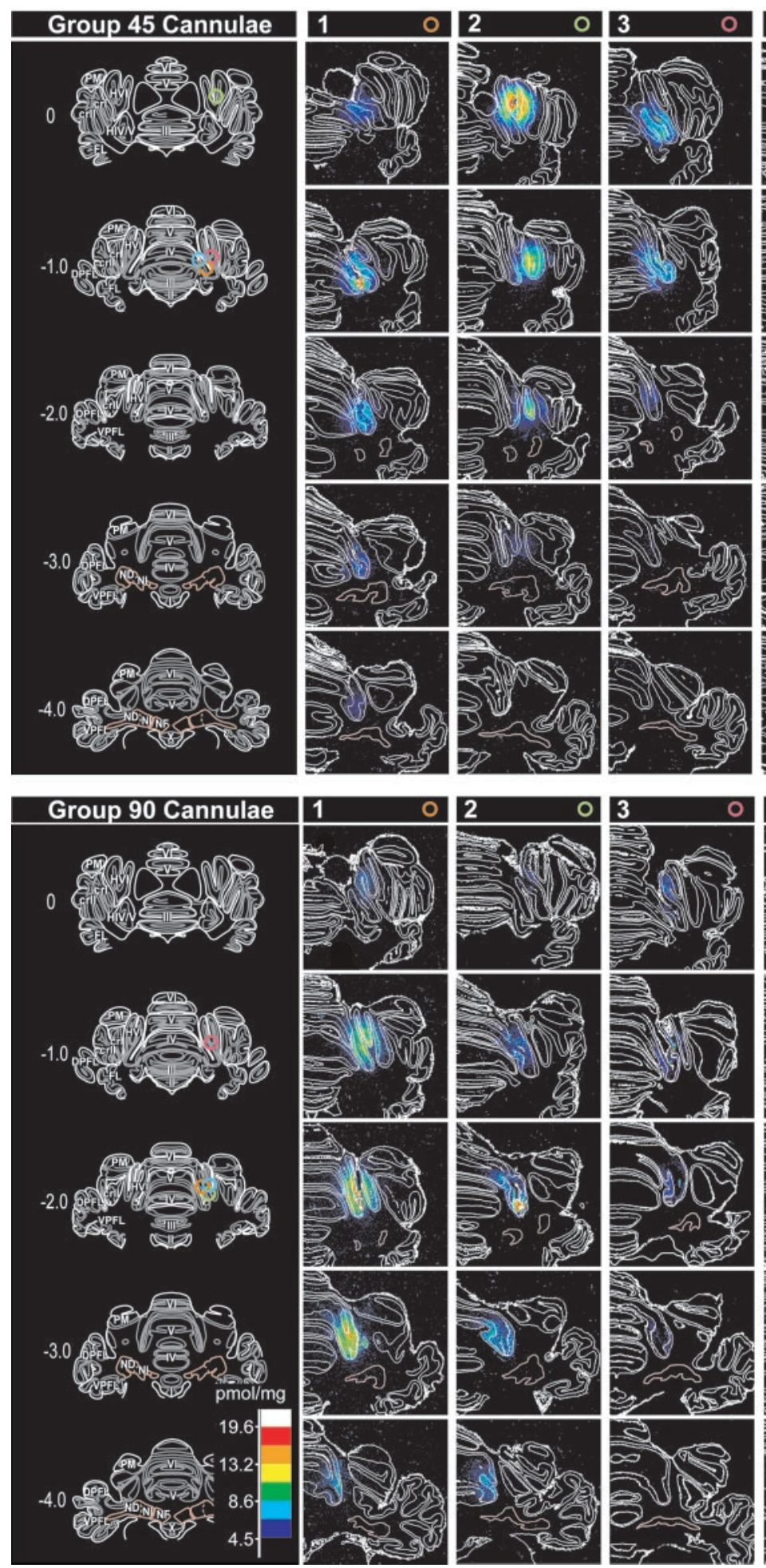

Figure 2. Localization of muscimol infusions revealed by ${ }^{3} \mathrm{H}$ autoradiography. The spread of $\left[{ }^{3} \mathrm{H}\right]$ muscimol revealed by autoradiography on transverse sections of cerebellum for each subject is shown. Concentration of the bound drug is indicated by the color code (see inset calibration) in picomoles of muscimol per milligrams of tissue equivalent. On the left are labeled, standard sections at equivalent coronal levels. The cerebellar nuclei are outlined in pink. crl and crll, Crus 1 and 2 (of ansiform lobe); DPFL, dorsal paraflocculus; FL, flocculus; HIV-V, HVI, hemispheral lobules 4-5 and 6 (of Larsell); ND, dentate nucleus; NF, fastigial nucleus; NI, interpositus nucleus; PM, paramedian lobe; VPFL, ventral paraflocculus; II-X, vermis lobules 2-10 (of Larsell).

To enable this control, the Nissl-stained sections were examined critically, and subjects with extensive, cannulation-related cortical damage in HVI were excluded from further analysis.

Of the 27 cortex-implanted subjects, 4 were rejected on crite-
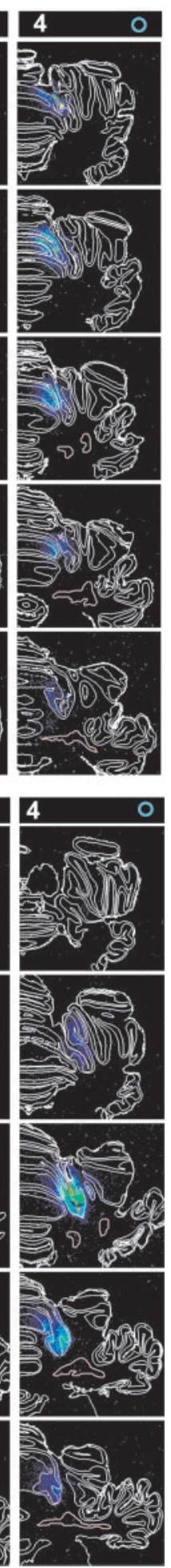

rion 1,3 were rejected on criterion 2 , and 5 were rejected on criterion 3 , leaving 4 subjects in group 45,4 subjects in group 90 , and 7 in group $S$.

Memory consolidation is impaired by intracortical muscimol infusions given $45 \mathrm{~min}$, but not $90 \mathrm{~min}$, after training Infusions of muscimol ( $7 \mathrm{nmol} ; 2 \mu \mathrm{l})$ into lobule HVI of the cerebellar cortex $45 \mathrm{~min}$ after training severely impaired learning, but infusions delayed by $90 \mathrm{~min}$ did not. The learning impairment induced by 45 min delayed muscimol was similar to that induced by 5 min delayed muscimol, reported previously (Attwell et al., 2002) (Fig. 4). Across Phases 1 and 2, there were significant group differences $(H=12.780$; $\mathrm{df}=3 ; p=0.005)$. Groups 5 and 45 were significantly different from control group $S(Q=3.121, p<0.05 ; \mathrm{Q}=2.777, p<$ 0.05 , respectively), but group 90 was not $(Q=1.242, p>0.05)$. The impairment of learning resulting from interference with post-training processes is clearly evident on session 5 , the first training session that was not followed by muscimol infusion. On this session, there was a significant difference between groups $\left(F_{(3,19)}=5.326\right.$; $p=0.010)$. Again, groups 5 and 45 were significantly different from control group $S(t=3.794, p<0.01 ; t=2.412, p<0.01$, respectively), but group 90 was not $(t=$ $1.1048, p>0.05$ ). Although the difference was not significant, there was a trend toward CR frequencies lower than those for the controls in the group 90 subjects in sessions 3,4 , and 5 .

Because all subjects reached asymptote, none could have sustained significant cannulation-related damage. Furthermore, the effects of cortical muscimol were fully reversible because they caused no long-lasting impairment of essential function. Importantly, the finding that group 90 subjects acquired CRs at rates similar to those of controls reveals that four daily infusions of muscimol had no significant cumulative effects to impair learning, and the effects of muscimol evidently dissipated entirely within $24 \mathrm{hr}$, before the next session of training began. Thus, the learning impairment in the group 45 and group 5 subjects must relate to a retrograde interference with post-training processes rather than anterograde interference with training sessions on each following day.

Time window of muscimol-sensitive consolidation processes

The results of the Phase 4 testing are presented in Figure 5, with the drug infusion start points offset by a time equivalent to their delays in Phase 1. For all groups, drug effects began within a few 
minutes of infusion, and performance fell to $\sim 50 \%$ within $30-50 \mathrm{~min}$ and fell to zero after $2 \mathrm{hr}$. There was some recovery after 8 hr in groups 5 and 90 and full recovery after $24 \mathrm{hr}$.

CR performance indicates the muscimol effects over time in Phase 4 and provides an estimate of the drug action in each subject during the preceding Phase 1, when consolidation processes were targeted. The rate of performance decline in groups 5 and 45 was very similar, although offset by $40 \mathrm{~min}$ for the latter. Because consolidation was similarly affected in both of these groups, it appears that the $\mathrm{GABA}_{\mathrm{A}}$-sensitive processes critical for consolidation do not begin immediately after the training session. Consolidation was not significantly impaired in group 90 subjects, so it must have been mostly complete before the drug induced significant functional inhibition in this group. The small trend toward lower CR frequencies across sessions 3, 4, and 5 for group 90 does indicate, however, that a small amount of consolidation continues beyond this time. Thus, the majority of critical consolidation processes must occur within a defined posttraining time window indicated by the performance-time space between the disruption profiles of group 45 and group 90 subjects (Fig. 5, hatched area), and the maximum temporal range of this space is $\sim 1-2.5 \mathrm{hr}$ after infusion. Because consolidation would have been disrupted when the depth of $\mathrm{GABA}_{\mathrm{A}}$ agonist reached a critical level, the actual temporal window would be shorter than this maximum range. If, for example, the critical drug level corresponds to performance decrements of $\sim 50 \%$, then, by interpolation from Figure 5, the critical consolidation time window is 60-120 min after training.

\section{Discussion}

We identify a time window beginning $\sim 1 \mathrm{hr}$ after the end of the conditioning session and closing $\sim 1 \mathrm{hr}$ later. During this period, consolidation of NMR conditioning is sensitive to cerebellar cortical application of the $\mathrm{GABA}_{\mathrm{A}}$ receptor agonist muscimol. This sensitivity may be limited to manipulations of GABAergic transmission or it may be more general. Previous studies (Hernandez and Powell, 1983; Scavio et al., 1992) suggest that consolidation of this same motor memory is sensitive to a range of substances delivered systemically. Amphetamine, chlorpromazine, and scopolamine retard, and the NMDA receptor antagonist ketamine facilitates, NMR conditioning when infused immediately but not when delivered $2 \mathrm{hr}$ after training. Other time delays were not tested, so they would not have uncovered a delayed onset of consolidation, as for the $\mathrm{GABA}_{\mathrm{A}}$ receptor sensitive process revealed here, but the $2 \mathrm{hr}$ end points are strikingly similar.

\section{On muscimol and cerebellar mechanisms of consolidation}

As in our original demonstration of a cerebellar cortex-mediated consolidation process (Attwell et al., 2002a), we again used muscimol as a cortical inactivator, this time to define the temporal properties of consolidation. Compared with protein synthesis inhibitors (PSIs) used in related studies (Bracha et al., 1998; Gomi et al., 1999), the use of this receptor ligand had two advan-


Figure 3. Cannula locations. Cannula tip positions for all subjects in groups $S, 45$, and 90 and group 5 [from Attwell et al.



Figure 4. Cortical muscimol effects on learning. Acquisition of conditioning, expressed as session \%CRs for groups S, 5 [replotted from Attwell et al. (2002a)], 45, and 90.

tages. First, it allowed autoradiographic assessment of the spread of drug (Fig. 3) as a strong internal control ensuring localization to cortical lobule HVI. Second, it permitted a final performance test (Phase 4), so the consolidation time window could be estimated from the performance-time space revealed in Figure 5.

Although the use of muscimol allowed a precise characterization of the time course of these consolidation processes, it un- 




Figure 5. Effects of muscimol on CR performance provide a measure of the temporal window for previous consolidation deficits. CR performance levels from Phase 4 testing are shown. The infusion time points (arrows) for each group are offset on the $x$-axis by a time equivalent to their delay in Phase 1 so the performance decline estimates temporal aspects of the drug effects, as they would have occurred in Phase 1. Consolidation was similarly impaired in groups 5 and 45 , and much less in group 90, so essential consolidation processes occur in the performance-time space indicated by hatching. If the critical drug level for consolidation effects corresponded to performance decrements of $50 \%$, then the critical consolidation time window would have been $60-120$ min after training.

doubtedly will have led to disturbed activity around the OCNO loop by depression of the spontaneous activity of Purkinje cells (Attwell et al., 2002a). So the disturbance of consolidation that we report here, and previously, might be attributed to interference with "perseverative" activity around the loop or a shifting of information from cortical to nuclear levels. Our previous finding that post-training, muscimol inactivation of the cerebellar nuclei did not disturb consolidation, despite the inevitable OCNO loop disturbance and the occluded GABAergic signaling from cortex to nuclei, was evidence against this suggestion and so too are the current findings. Perseverative processes of consolidation (Müller and Pilzecker, 1900), as proposed for episodic memory formation in which additional or subsidiary storage locations become engaged (Buzsaki, 1998; McClelland et al., 1995; Sirota et al., 2003), are active over several weeks (Riedel et al., 1999; Shimizu et al., 2000). The consolidation time window identified here is short at just $2 \mathrm{hr}$, similar to consolidation time windows identified using local infusions of PSIs in other memory systems (Freeman et al., 1995; Schafe and LeDoux, 2000). Because the application of PSIs impairs consolidation processes at the infusion site, the similarity of the temporal windows identified here and with PSIs in the other studies is consistent with the suggestion that local, intracortical consolidation processes for NMR conditioning were affected here.

Because group 90 subjects consolidated relatively normally, the effects of muscimol could not be anterograde on the following training session. Thus, the group 45 (and previous group 5) muscimol effects were retrograde on the previous session. There are three main possibilities for these retrograde amnestic mechanisms. First, inhibition of the postsynaptic neuron by the $\mathrm{GABA}_{\mathrm{A}}$ receptor agonist may have directly compromised postsynaptic processes essential for consolidation. Second, the $\mathrm{GABA}_{\mathrm{A}}$ receptor agonist will have disturbed local intracortical activity that could be important for consolidation. For example, information transmission from granule cell to Purkinje cell and granule cell theta activity (D'Angelo et al., 2001) would be strongly inhibited.
Although oscillatory activity has not been directly linked to memory consolidation in the cerebellum, it is strongly implicated in hippocampal consolidation processes (Sirota et al., 2003). Third, the change of cortical activity produced by muscimol would provide a different "context" signal. If the cerebellum begins to compensate for this new context, then the new learning could occlude the recent plasticity for NMR conditioning, still labile for up to 2 $\mathrm{hr}$ after the session. A similar interference with recent motor memory is seen when a second, conflicting task is learned within $4 \mathrm{hr}$ of the first (Brashers-Krug et al., 1996).

The leading candidate mechanism for memory storage in the cerebellar cortex is parallel fiber long-term depression (LTD) (Albus, 1971; Gilbert, 1975; Ito, 1982; Raymond et al., 1996; Yeo and Hesslow, 1998; Hansel et al., 2001; Koekkoek et al., 2003; Linden, 2003). There is little to suggest, from in vitro studies, that after induction there is a delayed $\mathrm{GABA}_{\mathrm{A}}$-sensitive stabilization phase, but a recent in vivo study has revealed a parallel fiberPurkinje cell plasticity with very similar temporal properties (Jörntell and Ekerot, 2002). Purkinje cell cutaneous receptive fields were significantly decreased by pairing parallel fiber beam stimulation with naturally occurring, spontaneous climbing fiber activation. Parallel fiber stimulation unrelated to climbing fiber inputs resulted in significant expansion of the Purkinje cell cutaneous receptive fields. The parallel fiber-Purkinje cell synaptic changes underlying these long-lasting receptive field changes began slowly and reached asymptote 1-2 hr later (Jörntell and Ekerot, 2002), a time window very similar to that of muscimolsensitive consolidation processes reported here.

\section{On the completeness of consolidation block and the sufficiency of cortical consolidation mechanisms}

Groups S and 90 both reached asymptotic levels of CR performance on sessions 6-7, whereas groups 45 and 5 reached asymptote on sessions 8-9. Thus, manipulation of post-training processes in Phase 1 for these short delay groups did not produce a learning impairment directly equivalent to the complete loss of those four training sessions. Similarly, in other studies, subjects with cortical or nuclear inactivations effective during each of four daily training sessions, to prevent acquisition of conditioning, also go on to learn somewhat more rapidly than naive subjects (Hardiman et al., 1996; Attwell et al., 2001), with savings equivalent to about one session of training. In the present study, however, the savings are more closely equivalent to two sessions of training for the group 5 and 45 subjects, so some memory storage outside the cerebellar cortex cannot be ruled out.

Electrophysiology has revealed changes in the cerebellar cortical flocculus (Ito, 1982) and at floccular target neurons in the medial vestibular nucleus during gain modification of the horizontal vestibulo-ocular reflex (VOR) (Miles and Lisberger, 1981; Raymond et al., 1996; Raymond, 1998), and electrophysiology combined with muscimol inactivation of the flocculus has presented a strong case for cortical and vestibular nucleus changes during similar gain modifications of the vertical VOR (Zhang et al., 1995a,b), indicating that there is learning-related plasticity in the cerebellar cortex and at its efferent targets. Therefore, duallevel learning processes in the cerebellar cortex and in the cerebellar nuclei might mediate eyeblink-NMR conditioning (Raymond et al., 1996). For eyeblink conditioning, it is suggested that excitatory mossy fiber collateral synaptic input to the cerebellar nuclei could be potentiated, allowing increased drive from the CS to the motor pools. Cortical learning of CS-US timing relationships would then provide appropriate inhibitory control over the nuclei to sculpt the CR (Medina et al., 2001, 2000). Claims for this 
form of nuclear plasticity in eyeblink conditioning depend on the unmasking of short latency, CS-driven responses (SLCRs) by disabling cerebellar cortical inhibition by lesion or neuropharmacological methods (Perrett et al., 1993; Garcia and Mauk, 1998). The conditions necessary for generating SLCRs are poorly understood. In some instances, infusions of the $\mathrm{GABA}_{\mathrm{A}}$ receptor antagonist picrotoxin at the cerebellar nuclei have released SLCRs (Garcia and Mauk, 1998; Medina et al., 2001), but in other instances they have not (Attwell et al., 2002b; Bao et al., 2002). Successive applications of muscimol and picrotoxin to the cerebellar nuclei reportedly block cortical inhibition but balance nuclear excitability to release SLCRs (Bao et al., 2002). The specific suggestion that this nuclear learning involves potentiation of excitatory mossy fiber collateral input is consistent with morphological evidence of synaptic changes in the cerebellar nuclei after eyeblink conditioning (Kleim et al., 2002) but not with recent in vitro studies. These have shown long-term potentiation and LTD at inhibitory synapses on cerebellar nuclear neurons and usedependent post-synaptic excitability changes (Aizenman et al., 1998, 2000).

With this range of experimental evidence, firm conclusions on the presence and importance of learning-related plasticity in the cerebellar nuclei would be premature. Certainly, our own evidence does not exclude it; however, the present study demonstrates clear evidence for consolidation processes mediated by the cerebellar cortex, and they occur within a relatively discrete $2 \mathrm{hr}$ time window. This identification now allows studies in which selective, but short-lasting, substances that target both cellsurface receptors and intracellular molecules are applied. With the recent identification of the importance of Purkinje cell protein kinase C for eyeblink conditioning (Koekkoek et al., 2003), parallel fiber LTD is an obvious experimental target for further analysis of cerebellar cortical memory consolidation mechanisms.

\section{References}

Aizenman CD, Manis PB, Linden DJ (1998) Polarity of long-term synaptic gain change is related to postsynaptic spike firing at a cerebellar inhibitory synapse. Neuron 21:827-835.

Aizenman CD, Huang EJ, Manis PB, Linden DJ (2000) Use-dependent changes in synaptic strength at the Purkinje cell to deep nuclear synapse. Prog Brain Res 124:257-273.

Albus JS (1971) A theory of cerebellar function. Math Biosci 10:25-61.

Andersson G, Garwicz M, Hesslow G (1988) Evidence for a GABAmediated cerebellar inhibition of the inferior olive in the cat. Exp Brain Res 72:450-456.

Arikan R, Blake NMJ, Erinjeri JP, Woolsey TA, Giraud L, Highstein SM (2002) A method to measure the effective spread of focally injected muscimol into the central nervous system with electrophysiology and light microscopy. J Neurosci Methods 118:51-57.

Attwell PJ, Rahman S, Yeo CH (2001) Acquisition of eyeblink conditioning is critically dependent on normal function in cerebellar cortical lobule HVI. J Neurosci 21:5715-5722.

Attwell PJ, Cooke SF, Yeo CH (2002a) Cerebellar function in consolidation of a motor memory. Neuron 34:1011-1020.

Attwell PJ, Ivarsson M, Millar L, Yeo CH (2002b) Cerebellar mechanisms in eyeblink conditioning. Ann NY Acad Sci 978:79-92.

Bao S, Chen L, Kim JJ, Thompson RF (2002) Cerebellar cortical inhibition and classical eyeblink conditioning. Proc Natl Acad Sci USA 99:1592-1597.

Bracha V, Irwin KB, Webster ML, Wunderlich DA, Stachowiak MK, Bloedel JR (1998) Microinjections of anisomycin into the intermediate cerebellum during learning affect the acquisition of classically conditioned responses in the rabbit. Brain Res 788:169-178.

Brashers-Krug T, Shadmehr R, Bizzi E (1996) Consolidation in human motor memory. Nature 382:252-255.

Buzsaki G (1998) Memory consolidation during sleep: a neurophysiological perspective. J Sleep Res 7 [Suppl 1]:17-23.
D’Angelo E, Nieus T, Maffei A, Armano S, Rossi P, Taglietti V, Fontana A, Naldi G (2001) Theta-frequency bursting and resonance in cerebellar granule cells: experimental evidence and modeling of a slow $\mathrm{K}^{+}$dependent mechanism. J Neurosci 21:759-770.

Freeman FM, Rose SP, Scholey AB (1995) Two time windows of anisomycin-induced amnesia for passive avoidance training in the dayold chick. Neurobiol Learn Mem 63:291-295.

Garcia KS, Mauk MD (1998) Pharmacological analysis of cerebellar contributions to the timing and expression of conditioned eyelid responses. Neuropharmacology 37:471-480.

Gilbert P (1975) How the cerebellum could memorise movements. Nature 254:688-689.

Gomi H, Sun W, Finch CE, Itohara S, Yoshimi K, Thompson RF (1999) Learning induces a CDC2-related protein kinase, KKIAMRE. J Neurosci 19:9530-9537.

Gormezano I, Schneiderman N, Deaux E, Fuentes I (1962) Nictitating membrane: classical conditioning and extinction in the albino rabbit. Science 138:33-34.

Hansel C, Linden DJ, D’Angelo E (2001) Beyond parallel fiber LTD: the diversity of synaptic and non-synaptic plasticity in the cerebellum. Nat Neurosci 4:467-475.

Hardiman MJ, Ramnani N, Yeo CH (1996) Reversible inactivations of the cerebellum with muscimol prevent the acquisition and extinction of conditioned nictitating membrane responses in the rabbit. Exp Brain Res 110:235-247.

Hernandez LL, Powell DA (1983) Naloxone induces multiple effects on aversive Pavlovian conditioning in rabbits. Behav Neurosci 97:478-491.

Ito M (1982) Cerebellar control of the vestibulo-ocular reflex around the flocculus hypothesis. Annu Rev Neurosci 5:275-296.

Jörntell H, Ekerot CF (2002) Reciprocal bidirectional plasticity of parallel fiber receptive fields in cerebellar Purkinje cells and their afferent interneurons. Neuron 34:797-806.

Kleim JA, Freeman Jr JH, Bruneau R, Nolan BC, Cooper NR, Zook A, Walters D (2002) Synapse formation is associated with memory storage in the cerebellum. Proc Natl Acad Sci USA 99:13228-13231.

Koekkoek SK, Hulscher HC, Dortland BR, Hensbroek RA, Elgersma Y, Ruigrok TJ, De Zeeuw CI (2003) Cerebellar LTD and learningdependent timing of conditioned eyelid responses. Science 301:1736-1739.

Krupa DJ, Thompson JK, Thompson RF (1993) Localization of a memory trace in the mammalian brain. Science 260:989-991.

Linden DJ (2003) Neuroscience. From molecules to memory in the cerebellum. Science 301:1682-1685.

Marr D (1969) A theory of cerebellar cortex. J Physiol (Lond) 202:437-470.

McClelland JL, McNaughton BL, O'Reilly RC (1995) Why there are complementary learning systems in the hippocampus and neocortex: insights from the successes and failures of connectionist models of learning and memory. Psychol Rev 102:419-457.

Medina JF, Garcia KS, Nores WL, Taylor NM, Mauk MD (2000) Timing mechanisms in the cerebellum: testing predictions of a large-scale computer simulation. J Neurosci 20:5516-5525.

Medina JF, Garcia KS, Mauk MD (2001) A mechanism for savings in the cerebellum. J Neurosci 21:4081-4089.

Miles FA, Lisberger SG (1981) Plasticity in the vestibulo-ocular reflex: a new hypothesis. Annu Rev Neurosci 4:273-299.

Müller GE, Pilzecker A (1900) Experimentalle Beiträge zur lehre vom Gedächtnis. Z Psychol Ergänzungsband 1:1-300.

Perrett SP, Ruiz BP, Mauk MD (1993) Cerebellar cortex lesions disrupt learning-dependent timing of conditioned eyelid responses. J Neurosci 13:1708-1718.

Raymond JL (1998) Learning in the oculomotor system: from molecules to behavior. Curr Opin Neurobiol 8:770-776.

Raymond JL, Lisberger SG, Mauk MD (1996) The cerebellum: a neuronal learning machine? Science 272:1126-1131.

Riedel G, Micheau J, Lam AG, Roloff E, Martin SJ, Bridge H, Hoz L, Poeschel B, McCulloch J, Morris RG (1999) Reversible neural inactivation reveals hippocampal participation in several memory processes. Nat Neurosci 2:898-905.

Scavio MJ, Clift PS, Wills JC (1992) Posttraining effects of amphetamine, chlorpromazine, ketamine, and scopolamine on the acquisition and extinction of the rabbit's conditioned nictitating membrane response. Behav Neurosci 106:900-908. 
Schafe GE, LeDoux JE (2000) Memory consolidation of auditory Pavlovianfear conditioning requires protein synthesis and protein kinase $\mathrm{A}$ in the amygdala. J Neurosci 20:RC96(1-5).

Shimizu E, Tang YP, Rampon C, Tsien JZ (2000) NMDA receptordependent synaptic reinforcement as a crucial process for memory consolidation. Science 290:1170-1174.

Sirota A, Csicsvari J, Buhl D, Buzsaki G (2003) Communication between neocortex and hippocampus during sleep in rodents. Proc Natl Acad Sci USA 100:2065-2069.

Voogd J, Glickstein M (1998) The anatomy of the cerebellum. Trends Neurosci 21:370-375.

Welsh JP, Harvey JA (1998) Acute inactivation of the inferior olive blocks associative learning. Eur J Neurosci 10:3321-3332.
Yeo CH, Hardiman MJ (1992) Cerebellar cortex and eyeblink conditioning: a reexamination. Exp Brain Res 88:623-638.

Yeo CH, Hesslow G (1998) Cerebellum and conditioned reflexes. Trends Cogn Sci 2:322-330.

Zhang Y, Partsalis AM, Highstein SM (1995a) Properties of superior vestibular nucleus flocculus target neurons in the squirrel monkey. I. General properties in comparison with flocculus projecting neurons. J Neurophysiol 73:2261-2278.

Zhang Y, Partsalis AM, Highstein SM (1995b) Properties of superior vestibular nucleus flocculus target neurons in the squirrel monkey. II. Signal components revealed by reversible flocculus inactivation. J Neurophysiol 73:2279-2292. 